\title{
Assessment and Risk Management of Potential Hazards by Failure Modes and Effect Analysis (FMEA) Method in Yazd Steel Complex
}

\author{
Mehrzad Ebrahemzadih1,2, G. H. Halvani³, Behzad Shahmoradi², Omid Giahi1,2* \\ ${ }^{1}$ Department of Occupational Health, Faculty of Health, Kurdistan University of Medical Sciences, Sanandaj, Iran \\ ${ }^{2}$ Kurdistan Environmental Health Research Center, Kurdistan University of Medical Sciences, Sanandaj, Iran \\ ${ }^{3}$ Departments of Occupational Health, Faculty of Health, Shahid Sadoghi University of Medical Sciences, Yazd, Iran \\ Email: *omidgi71@yahoo.com
}

Received 8 June 2014; revised 8 July 2014; accepted 8 August 2014

Copyright (C) 2014 by authors and Scientific Research Publishing Inc.

This work is licensed under the Creative Commons Attribution International License (CC BY). http://creativecommons.org/licenses/by/4.0/

(c) (i) Open Access

\begin{abstract}
Background: Failure mode and effect analysis (FMEA) is a widely used quality improvement and risk assessment tool in manufacturing. The aim of this study is to assess potential hazards by failure modes and effect analysis (FMEA) method in Yazd Steel Complex. Methods: In this descriptive study, we evaluated the risks in different parts of the complex by using FMEA method and by using FMEA Worksheets (PFMEA) derived from the standard (MIL_STD-882). Failure modes and the various components and effects as using quantitative score to the risk priority (RPN) were obtained. PFMEA worksheets were completed and, we reevaluated the weaknesses part of the system. Activities related to each from the different parts of Yazd Steel Complex by using the scores risk priority (RPN) were evaluated. Then the results obtained by using SPSS software were performed by evaluation and analysis. Results: The findings showed that the steel maker lime unite and steel making ingot casting achieved the highest of RPN before and after corrective actions measures $(490,168)$ and environmental health unite and roll styles unite achieved the lowest of RPN before and after corrective actions measures $(28,20)$. Conclusions: The results show that the FMEA technique can identify a higher number of hazards than any other technique. The important point is that selection of an appropriate technique plays an important role in identifying a higher number of hazards.
\end{abstract}

\section{Keywords}

Failure Modes and Effects Analysis (FMEA), Risk Management, Steel, Risk

\footnotetext{
${ }^{*}$ Corresponding author.
}

How to cite this paper: Ebrahemzadih, M., Halvani, G.H., Shahmoradi, B. and Giahi, O. (2014) Assessment and Risk Management of Potential Hazards by Failure Modes and Effect Analysis (FMEA) Method in Yazd Steel Complex. Open Journal of Safety Science and Technology, 4, 127-135. http://dx.doi.org/10.4236/ojsst.2014.43014 


\section{Introduction}

In the past few decades, many actions and research works have been undertaken to prevent potential accidents and to promote safety in the chemical processes; the output of these measures is the systematic management of safety in these processes. One of the key elements of safety management systems is to identify hazards, to assess risks and their control, which helps security professionals to investigate the ability of rational decision to reduce the risk and severity of accidents and their consequences [1].

Failure mode and effects analysis (FMEA) is commonly defined as "a systematic process for identifying potential design and process failures before they occur, with the intent to eliminate them or minimize the risk associated with them”. The FMEA technique was first reported in the 1920s but its use has only been significantly documented since the early 1960s. It was developed in the USA in the 1960s by national aeronautics space agency (NASA) as a means of addressing a way to improve the reliability of military equipment [2].

Despite the importance of risk assessment as a scientific basis for national and international activities, this category has different meanings among people and experts in various disciplines, and is often controversial and incorrect interpretations. Diversity and distribution of scientific topics, definition of risk assessment, the distinction between risk assessment and risk management, et al. are among the reasons that have offered different interpretations of the concept of risk assessment. Based on objectives, data, resources, and other factors for risk assessment, methods and definitions are introduced. Hazard identification and safety evaluation have several methods, including safety audits patrols and inspections of HAZOP, JSA, and FMEA. An OSHA guideline is one of the quality tools that every manager needs to be familiar with [3].

Every day in the United States, a large number of workers are injured or killed at work. Considering work place conditions, providing proper work procedure, and training all workers are among suitable and useful strategies to prevent disease incidence, injury and trauma [4]. Risk management includes techniques to identify, assess and control risk, as other tools are multifarious. Generally it can be divided into two categories: qualitative and quantitative; qualitative methods are usually applied to small companies with a low number of activities, whereas quantitative methods are usually used for large organizations with high activity. One of the few ways to identify, assess and control risks is FMEA method [5].

In 1950, FMEA method was established by engineers for reliability and safety assessment in military systems. It was quickly spread so that it was used to evaluate safety of Concorde and Airbus aircraft in America and France respectively. This method was also developed in nuclear safety after the Maryland disaster [6]. Failure mode and effects analysis (FMEA) is a comprehensive engineering technique that manufacturers are able to improve the quality, reliability, and safety of their products through applying this technique [7]. In particular, FMEA technique is used to identify, define, and eliminate known and potential failures, problems and errors in the products, programs, systems and services before they reach the customer.

FMEA is a systematic method, which is applied because of the following reasons:

1) To identify and prioritize potential failure modes in a system, product, process, or service;

2) To define and run measures in order to eliminate or reduce the incidence of potential failure modes;

3) To record analysis results in order to provide a comprehensive reference for solving future issues and problems [8].

FMEA could be described as a structured method to find and identify failure modes in a system, object, or an activity and calculation of the failure effects on upper steps [9] [10].

According to the 2011 disaster, which killed 14 and injured 5 people and the importance of steel industry as well as the preservation of labor force, we conducted a comprehensive and targeted study.

\section{Materials and Methods}

This is a descriptive study conducted in Yazd Steel Complex. In this study, we evaluated the risks in different parts of the complex using FMEA method. Using FMEA Worksheets derived from the standard (MIL_STD882), we obtained failure modes along with its different components and failure effects in quantity using risk priority number (RPN) equation and PFMEA worksheets were completed. Finally, we reevaluated the weaknesses of the system. Activities related to each of the different parts of Yazd Steel Complex were studied using RPN equation. The result of the evaluation and analysis was performed using SPSS software.

\section{-System description}

After visiting and studying different parts of Yazd Steel Complex, risks involved in the steel complex were examined in detail and likelihood, severity, and frequency of exposure were quantitatively studied. Moreover, 
the risk of each activity was obtained and in another part, the control measures were expressed. Later, we again stated the likelihood, severity, and frequency of exposure and risk reduced. At the end of this study, we would present tables of the risk probability, risk severity, frequency of exposure, and risk number obtained before control measures and after control measures separately. Figure 1 shows the FMEA process.

\section{-RPN methodology}

Decision making using RPN scoring and crisis level.

The RPN is a mathematical product of the severity, the occurrence and the detection. The number is used to identify the most critical failure mode, leading to corrective action [12].

RPN scoring is based on the fact that numbers with higher risk priority have priority for analyzing and resource allocation aimed at improvement, and the team should work on failure modes having a higher RPN. RPN is obtained by multiplying three factors of intensity, possibility of occurrence, and detection possibility [13]. It is calculated using Equation (1).

$$
\text { RPN }=\text { Severity } \times \text { Occurrenc } \times \text { Detection }
$$

RPN to evaluate the risk level of a component or process.

The RPN is obtained by finding the multiplication of three factors, which are the severity of the failure (S), the probability of occurrence (O) and the probability of detection (D). In this project, we used risk criterion number to determine the level of acceptable and unacceptable risk in RPN. Risk criterion is an index for separating acceptable and unacceptable risks in the system studied. A failure that its RPN number is greater than the risk criterion is considered as unacceptable risk and a failure that its RPN is lower than the risk criterion is called acceptable risk. This index is varied based on the laws and regulations of each organization and its ability to pay for needed projects costs.

\section{-Determination of the severity rate}

Severity is a rating corresponding to the seriousness of an effect of a potential failure mode. Severity or seriousness of the risk is considered just in case of "the effect"; reducing the risk severity is possible only through changing the process and the manner of performing activities.

\section{-Determination of the occurrence rate}

Occurrence is ranked according to the failure probability, which represents the relative number of failures anticipated during the design life of the item. The effects of a failure mode are normally described by the effects on the user of the product or as they would be seen by the user.

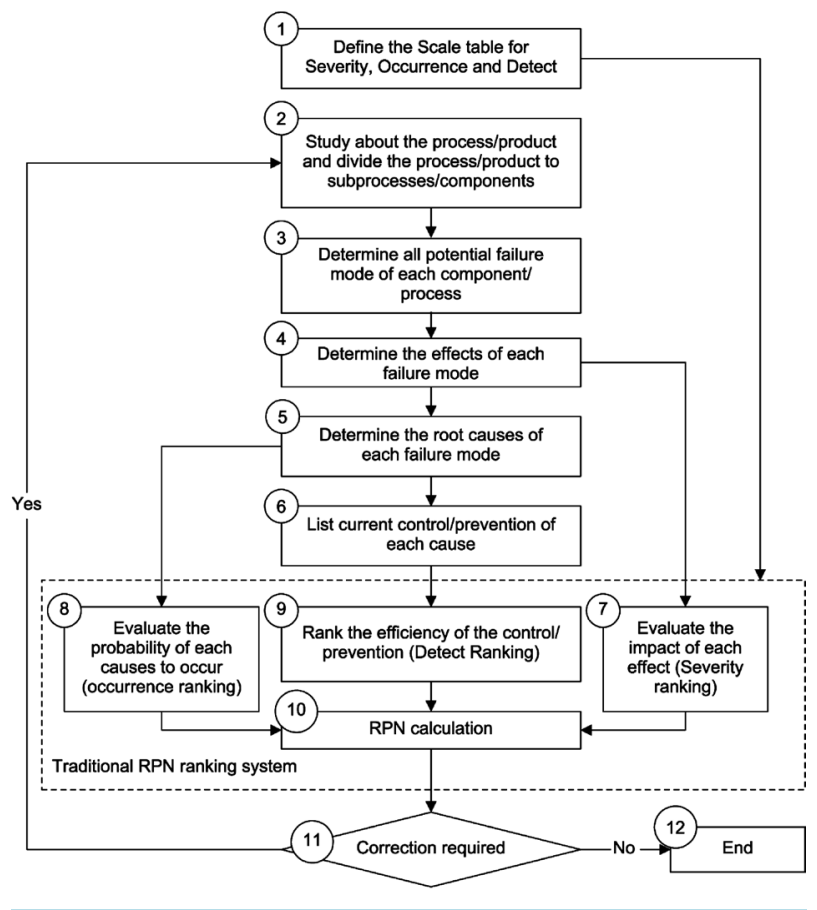

Figure 1. The traditional FMEA procedure [11]. 


\section{-Risk detection probability rate}

Detection possibility is an assessment of the ability existing to identify a cause/mechanism of a risk occurrence. In other words, detection possibility is a rating corresponding to the likelihood that the detection methods or current controls will detect the potential failure mode before the product is released for production for design, or for process before it leaves the production facility. Assessing control process of standards, requirements and laws of labor and how to apply them to achieve this number are very useful.

In the RPN methodology the parameters used to determine the "criticality" of an item failure mode are, the severity of its failure effects, its frequency of occurrence, and the likelihood that subsequent testing of the design will detect that the potential failure mode actually occurs. Tables 1-3 show the qualitative scales commonly used for the severity, the occurrence and the detect ability indexes [14].

Table 1. Severity guidelines for design FMEA (1 - 10 qualitative scale) [14].

\begin{tabular}{ccc}
\hline Effect & Rank & Criteria \\
\hline No & 1 & No effect \\
Very slight & 2 & Customer not annoyed \\
Slight & 3 & Customer slight annoyed \\
Minor & 4 & Customer experiences minor nuisance \\
Moderate & 5 & Customer experiences some dissatisfaction \\
Significant & 6 & Customer experiences discomfort \\
Major & 7 & Customer dissatisfied \\
Extreme & 8 & Customer very dissatisfied \\
Serious & 9 & Potential hazardous effect \\
Hazardous & 10 & Hazardous effect \\
\hline
\end{tabular}

Table 2. Occurrence guidelines for design FMEA (1 - 10 qualitative scale) [14].

\begin{tabular}{ccc}
\hline Effect & Rank & Criteria \\
\hline Almost never & 1 & Failure unlikely. History shows no failure \\
Remote & 2 & Rare number of failures likely \\
Very slight & 3 & Very few failures likely \\
Slight & 4 & Few failures likely \\
Low & 5 & Occasional number of failures likely \\
Medium & 6 & Medium number of failures likely \\
Moderately high & 7 & Moderately high number of failures likely \\
High & 8 & High number of failures likely \\
Very high & 9 & Very high number of failures likely \\
Almost certain & 10 & Failure almost certain \\
\hline
\end{tabular}

Table 3. Detectability guidelines for design FMEA (1 - 10 qualitative scale) [14].

\begin{tabular}{ccc}
\hline Effect & Rank & Criteria \\
\hline Almost certain & 1 & Proven detection methods available in concept stage \\
Very high & 2 & Proven computer analysis available in early design stage \\
High & 3 & Simulation and/or modeling in early stage \\
Moderately high & 4 & Tests on early prototype system elements \\
Medium & 5 & Tests on preproduction system components \\
Low & 6 & Tests on similar system components \\
Slight & 7 & Tests on product with prototypes and system components installed \\
Very slight & 8 & Proving durability tests on products with system components installed \\
Remote & 9 & Only unproven or unreliable technique(s) available \\
Almost impossible & 10 & No known techniques available \\
\hline
\end{tabular}


In this research work, we considered both risks with high RPN and low RPN having one or two abovementioned factors, i.e. while determining risk criterion and decision making for considering a failure within the acceptable or unacceptable risk domain, the team attention was not only towards RPN values but also each of the tree failure factors were assessed. For this purpose, a criterion was defined as the level of crisis. The crisis is a criterion that expresses the importance of a potential/actual risk in the system studied. In addition, it is used to measure the level of crisis in the system. Crisis grade is composed of normal, semi-critical, and critical levels which are explained in detail below:

Level 1: Normal level in which all of the three factors of RPN (especially the severity and probability of occurrence) have values less than 5. Or RPN number is very low and does not require corrective and preventive actions (however, according to the concerned engineer, the corrective/preventive action could be presented (usually RPN $<70$ )).

Level 2: Semi-critical level in which at least a factor of three factors of RPN (especially the severity and probability of occurrence) has a value greater than 5 but RPN is relatively low. In this case, corrective/preventive action is essential (typically $70<$ RPN $<140$ ).

Level 3: Critical level in which at least two factors of the three-factor of RPN have high values or RPN number is too high. Since this level has been considered for high RPN, it is obvious and clear that it has a corrective/preventative action (usually RPN > 140) [15].

\section{Results}

Table 4 and Table 5 summarize the results of implementing FMEA in Yazd Steel Complex. These tables tabu-

Tables 4. The sample FMEA work sheet in the steel making (unit of lime).

\begin{tabular}{|c|c|c|c|c|c|c|c|c|c|c|c|c|}
\hline \multicolumn{13}{|c|}{$\begin{array}{c}\text { FAILURE MODE AND EFFECTS ANALYSIS } \\
\text { Work sheet item: steel making (unit of lime) } \\
\text { Core team: Mehrzad Ebrahemzadih, G.H. Halvani, B. Shahmoradi }\end{array}$} \\
\hline & Process Function & Potential Failure Mode & $\begin{array}{c}\text { Potential Effect(s) } \\
\text { of Failure }\end{array}$ & $\mathrm{S}$ & $\mathbf{O}$ & $\mathbf{D}$ & RPN & Recommended Action(s) & $\begin{array}{c}\mathrm{S} \\
\mathbf{R E}\end{array}$ & $\begin{array}{c}\mathbf{O} \\
\mathbf{R E}\end{array}$ & $\begin{array}{c}\text { D } \\
\text { RE }\end{array}$ & $\begin{array}{c}\text { RPN } \\
\text { RE }\end{array}$ \\
\hline \multirow{2}{*}{1} & \multirow{2}{*}{ Furnace operator } & Dust & Lung damages & 7 & 5 & 5 & 175 & The use of respiratory mask & 2 & 5 & 5 & 50 \\
\hline & & Noise & Hearing damage & 7 & 4 & 5 & 140 & The use of ear plugs & 2 & 5 & 5 & 50 \\
\hline \multirow{2}{*}{2} & \multirow{2}{*}{$\begin{array}{l}\text { Raw ore charging } \\
\text { into the furnace }\end{array}$} & The fall basket Netscape & Death & 10 & 5 & 6 & 300 & Creating safeguards & 3 & 5 & 6 & 90 \\
\hline & & Rock fall & Fracture of lumbar & 6 & 5 & 4 & 120 & Creating safeguards + training & 3 & 4 & 4 & 48 \\
\hline 3 & Lime discharge & Dust & Lung damages & 7 & 8 & 5 & 280 & The use of respiratory mask & 3 & 7 & 5 & 105 \\
\hline \multirow{2}{*}{4} & \multirow{2}{*}{ Driving loaders } & Dust & Lung damages & 6 & 5 & 6 & 180 & The use of respiratory mask & 2 & 5 & 5 & 50 \\
\hline & & Noise & Hearing damage & 7 & 6 & 4 & 168 & The use of ear plugs & 3 & 5 & 3 & 30 \\
\hline
\end{tabular}

Tables 5. The sample FMEA work sheet in the steel making (IC unit-ingot casting).

\begin{tabular}{|c|c|c|c|c|c|c|c|c|c|c|c|c|}
\hline \multicolumn{13}{|c|}{$\begin{array}{c}\text { FAILURE MODE AND EFFECTS ANALYSIS } \\
\text { Work sheet item: steel making (IC unit-ingot casting) } \\
\text { Core team: Mehrzad Ebrahemzadih, G.H. Halvani, B. Shahmoradi }\end{array}$} \\
\hline \multicolumn{2}{|r|}{ Process Function } & \multirow{2}{*}{$\begin{array}{c}\text { Potential Failure Mode } \\
\text { The fall sand sacking }\end{array}$} & \multirow{2}{*}{$\begin{array}{c}\begin{array}{c}\text { Potential Effect(s) } \\
\text { of Failure }\end{array} \\
\text { Death }\end{array}$} & \multirow{2}{*}{$\begin{array}{l}S \\
10\end{array}$} & \multirow{2}{*}{$\begin{array}{l}0 \\
5\end{array}$} & \multirow{2}{*}{$\begin{array}{l}\mathbf{D} \\
\mathbf{3}\end{array}$} & \multirow{2}{*}{$\begin{array}{l}\text { RPN } \\
150\end{array}$} & Recommended Action(s) & $\begin{array}{c}\mathrm{S} \\
\mathbf{R E}\end{array}$ & $\begin{array}{c}\mathbf{O} \\
\mathbf{R E}\end{array}$ & $\begin{array}{c}\text { D } \\
\text { RE }\end{array}$ & $\begin{array}{c}\text { RPN } \\
\text { RE }\end{array}$ \\
\hline 1 & $\begin{array}{l}\text { Filling the sand } \\
\text { blasting tank }\end{array}$ & & & & & & & Alarm by crane & 10 & 5 & 2 & 100 \\
\hline \multirow[b]{2}{*}{2} & \multirow[b]{2}{*}{ Casting } & Infrared light & Cataract & 7 & 5 & 8 & 280 & The use of face shield & 7 & 3 & 6 & 126 \\
\hline & & High temperature & Burn & 4 & 6 & 9 & 216 & $\begin{array}{l}\text { The use of helmet } \\
\text { and gloves fireproof } \\
\text { and body shield }\end{array}$ & 2 & 6 & 8 & 96 \\
\hline 3 & $\begin{array}{l}\text { Checking the } \\
\text { furnace burners }\end{array}$ & Biting & Death & 10 & 5 & 4 & 200 & The use of detector & 8 & 4 & 2 & 64 \\
\hline \multirow{2}{*}{4} & \multirow{2}{*}{$\begin{array}{l}\text { Work in steel } \\
\text { making }\end{array}$} & Dust & Lung damages & 7 & 5 & 6 & 180 & The use of respiratory mask & 3 & 4 & 5 & 60 \\
\hline & & Noise & Hearing damage & 7 & 6 & 6 & 252 & The use of ear plugs & 3 & 5 & 5 & 75 \\
\hline
\end{tabular}


late the risks and their causes, severity and occurrence possibility of risks in two parts of steel making (unit of lime) and ingot casting in order to show the way of filling risk assessment sheets.

Graph 1 and Graph 2 show the risks involved in the systems before and after corrective actions in different units of Yazd Steel Complex.

\section{Discussion}

After determining the level of risk associated with different parts of the steel industry, the following results related to the MAX and MIN, mean and SD, RPN before and after corrective actions was defined with regard to the job in the process function (Table 6).

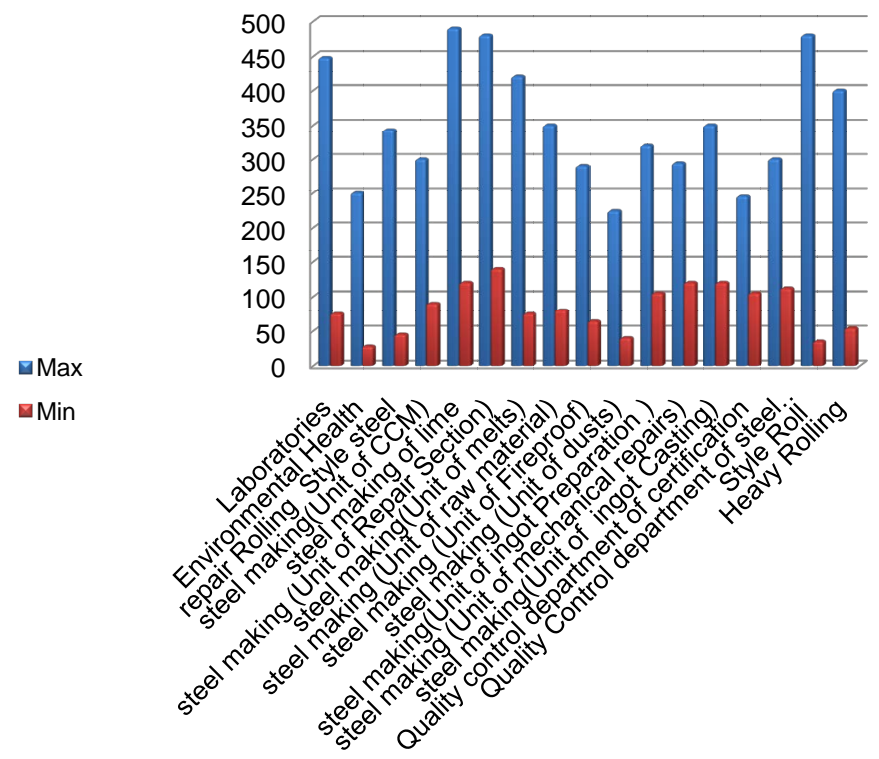

Graph 1. Risks evaluation before corrective actions in different units of Yazd Steel Complex.

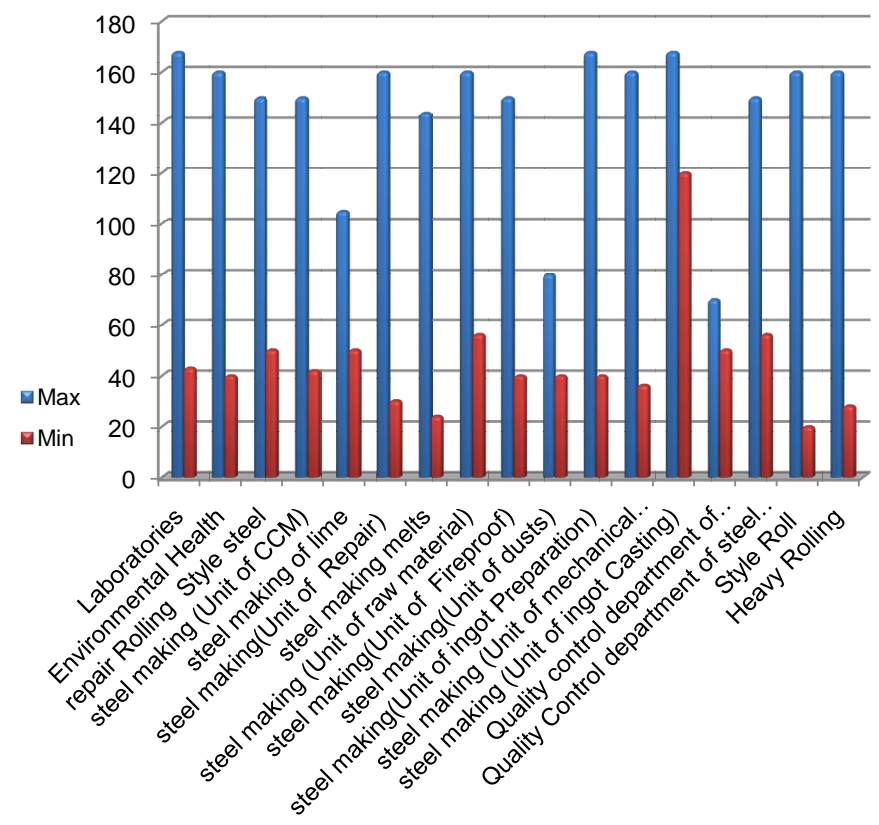

Graph 2. Risks evaluation after corrective actions in different units of Yazd Steel Complex. 
Table 6. Summary of results risk assessment by FMEA method.

\begin{tabular}{|c|c|c|c|c|c|c|}
\hline \multirow{2}{*}{$\begin{array}{l}\text { Parameters } \\
\text { RPN }\end{array}$} & \multirow{2}{*}{$\begin{array}{l}\text { Process } \\
\text { Function }\end{array}$} & \multirow{2}{*}{ MAX } & \multirow{2}{*}{$\begin{array}{l}\text { Process } \\
\text { Function }\end{array}$} & \multirow{2}{*}{ MIN } & \multicolumn{2}{|c|}{ Mean \pm SD } \\
\hline & & & & & MIN & MAX \\
\hline Before corrective actions & Steel making of lime & 490 & Department environmental health & 28 & $352 \pm 86.58$ & $82.82 \pm 34.61$ \\
\hline After corrective actions & Steel making ingot casting & 168 & Style roll & 20 & $144.88 \pm 30.09$ & $45 \pm 21.96$ \\
\hline
\end{tabular}

Although initially it seemed that there is no big and much risks in these sections and the subset employees persist this problem, our results indicated that there are many unknown hazards with a higher risk.

A part of the forms of hazard identification, harmful factors, and risk assessment at steel industry (lime unit).

Equipment failures analysis using FMEA provides the possibility to identify various factors having the potential to create conditions for the possibility of an accident or stop operating phases [16]. Because no preventive and control measures are conducted on them and finally one day they could cause an accident.

It is noteworthy that most of the known risks threaten the system while they could be eliminated or controlled easily and by spending the minimum cost. However, the accidents resulted from them could impose huge losses on the system [17]. FMEA is applied in the industry at all stages of an industrial project from the manufacturing stage to the production stage to improve product quality and productivity [18]. Given that the traditional approach to the design industry without considering the risk of accidents has caused many deficiency and failures in past, nowadays, in implementing industrial plans, especially in the early stages of design, FMEA technique has limited and minimized failures through identifying and assessing risks involved [19].

OSHA believes that the process of risk analysis should be at best as a team work with expertise in engineering and process operations. Moreover, it should involve at least one person from the workers, who has expertise and knowledge in the field of the method used to identify risks [20].

In a study, Rezvani showed that among the possible existing risks in milk company, noise from the production line equipment including tetra packing equipment and basket washing machine had the highest relative frequency (64\%) followed by hazards such as inhaling $\mathrm{NaOH}$ and acid fumes (32\%), and burns from acid and $\mathrm{NaOH}(32 \%)$. In this study, the number of employees studied was 28 and the number of hazards identified was 280 risks [21].

In another study in oil refining company, Asadi reported that the risk of falling from a height with a relative frequency of $12 \%$ and the risk of slipping with a relative frequency of $10 \%$ led to accidents. The total number of identified risks was 4250 cases [22]. Benjamin showed that accidents and disasters could be significantly prevented if during the production process of the system, FMEA could be launched and carefully managed at the beginning of the process [23].

In another study conducted by Ebrahimzadeh et al. at Shiraz Refinery, Iran, it was found that activities with low RPN have more priority than the activities with higher RPN in terms of severity. In addition, scoring high RPN in some activities such as handling and transportation of objects and milling, one can apply appropriate control measures to the level of acceptable risk indicating usefulness and effectiveness of FMEA method [24].

Naturally, not only organization culture but also community culture must booster safety. Economic condition of the organization is also an influencing factor on the risk assessment. Organizations in which productivity is low and revenue is not satisfactory, is not able to pay for safety. This, in turn, reduces the level of safety in the organization and would result in more accidents or disasters. These disaster themselves will bring about direct losses and reducing product quality and quantity. This means lower productivity and profits, and thus reducing the organization funding on safety. Organizational factors have also remarkable influences on the development or progression or system safety development [25].

\section{Conclusion}

In order to prevent potential accidents and improve safety in industrial processes, systematic management of safety is essential in these processes. It seems that the implementation of a documentation system for recording equipment deficiencies and events can be basic information needed to assess the subsequent safety ideally. In addition, performing preventive maintenance can reduce the possibility of the equipment defects and their consequences. Our results showed that compared with other methods of risk assessment, FMEA can identify more risks and an important point is that choosing an appropriate method plays a crucial role in identifying more risks. 


\section{References}

[1] Mirghiasi, Z. (2009) Hazard Identification and Risk Analysis. B.Sc. Graduation Thesis, Abadan Petrochemical Unit 300, PUT.

[2] Johnson, K.G. and Khan, M.K. (2003) A Study into the Use of the Process Failure Mode and Effects Analysis (PFMEA) in the Automotive Industry in the UK. Journal of Materials Processing Technology, 139, 348-356. http://dx.doi.org/10.1016/S0924-0136(03)00542-9

[3] Joy, J. (2004) Occupational Safety Risk Management in Australian Mining. Occupational Medicine, 54, 311-315.

[4] US Department of Labor, Occupational Safety and Health Administration (2001) Job Hazard Analysis. OSHA Publication.

[5] Russomanno, D.J., Bonnell, R.D. and Bowles, J.B. (1993) Functional Reasoning in a Failure Modes and Effects Analysis (FMEA) Expert-System. Proceedings of the Annual Reliability and Maintainability Symposium, Atlanta, 26-28 January 1993, 339-347.

[6] Chen, H.C. (1996) Failure Modes and Effects Analysis Training Manual. Personal Communication, Hen Technology Inc., USA.

[7] Huang, G.Q., Nie, M. and Mak, K.L. (1999) Web-Based Failure Mode and Effect Analysis. Computers \& Industrial Engineering, 37, 177-180. http://dx.doi.org/10.1016/S0360-8352(99)00049-2

[8] Wirth, R., Berthold, B., kramer, A. and Gerhard, P. (1996) Knowledge-Based Support of System Analysis for Analysis of Failure Modes and Effects. Engineering Applied Artificial Intelligence, 9, 219-229. http://dx.doi.org/10.1016/0952-1976(96)00014-0

[9] Rozenfeld, O., Sacks, R. and Rosenfeld, Y. (2009) CHASTE—Construction Hazard Analysis with Spatial and Temporal Exposure. Construction Management \& Economics, 27, 625-638. http://dx.doi.org/10.1080/01446190903002771

[10] SAE (2002) Potential Failure Mode and Effects Analysis in Design (Design FMEA), Potential Failure Mode and Effects in Manufacturing and Assembly Processes (Process FMEA), and Potential Failure Mode and Effects Analysis for Machinery (Machinery FMEA).

[11] Tay, K.M. and Lim, C.P. (2006) Fuzzy FMEA with a Guided Rules Reduction System for Prioritization of Failures. International Journal of Quality \& Reliability Management, 23, 1047-1066. http://dx.doi.org/10.1108/02656710610688202

[12] Palady, P. (1995) Failure Modes and Effects Analysis: Predicting \& Preventing Problems before They Occur. PT Publications Inc., Florida.

[13] International Electro Technical Commission (1991) IEC 60812: Analysis Techniques for System Reliability-Procedure for Failure Mode and Effects Analysis (FMEA).

[14] Narayanagounder, S. and Gurusami, K. (2009) A New Approach for Prioritization of Failure Modes in Design FMEA Using ANOVA. World Academy of Science, Engineering and Technology, 3, 477-484.

[15] USA Department of Defense (1980) Military Standard, Procedure for Performing a Failure Mode, Effects and Criticaly Analysis. Department of Defense, Washington DC, 27-33.

[16] Wirth, R., Berthold, B., Kramer, A. and Peter, G. (1996) Knowledge-Based Support of System Analysis for the Analysis of Failure Modes and Effects. Engineering Applications of Artificial Intelligence, 9, 219-229.

[17] Elmqvist, J. and Nadjm-Tehrani, S. (2008) Formal Support for Quantitative Analysis of Residual Risks in SafetyCritical Systems. Proceedings of HASE 2008, Nanjing, 3-5 December 2008, 154-164.

[18] Ale, B.J.M., Bellamy, L.J., Baksteen, H., Damen, M., Goossens, L.H.J., Hale, A.R., Mud, M., Oh, J., Papazoglou, I.A. and Whiston, J.Y. (2008) Accidents in the Construction Industry in the Netherlands: An Analysis of Accident Reports Using Storybuilder. Reliability Engineering and System Safety, 93, 1523-1533. http://dx.doi.org/10.1016/j.ress.2007.09.004

[19] FAA (Federal Aviation Administration) (2000) Lesson 5: Failure Modes and Effects Analysis. In: System Safety Handbook, 2.

[20] USA Department of Labor, Occupational Safety and Health Administration (OSHA) (2000) Process Safety Management, 10.

[21] Rezvani, Z. and Gholami, M. (2006) Identifying Analysis of Occupational Hazards in a Milk Company. 1st National Conference of Safety Engineering and Management, Tehran.

[22] Asadi, A. (2004) The Investigation Hazards Make Accidents in an Oil Refining Company. First Symposium of Occupational Health and Safety in Oil Refining Companies.

[23] Benjamin, P.C., Menzel, C.C., Mayer, R.J., Fillion, F., Futrell, M.T., Dewitte, P.S. and Lingineni, M. (1994) Informa- 
tion Integration for Concurrent Engineering, IDEF5 Method Report. http://www.idef.com/pdf/idef3_fn.pdf

[24] Ebrahimzadeh, M., Halvani, G.H., Mortazavi, M. and Soltani, R. (2011) Assessment of Potential Hazards by Failure Modes and Effect Analysis (FMEA) Method in Shiraz Oil Refinery. Occupational Medicine Journal, 3, 16-23.

[25] Darligton, J.F. and Booker, J.D. (2006) Development of a Design Technique for the Identification of Fatigue Initiating Features. Engineering Failure Analysis, 13, 809-876. 
Scientific Research Publishing (SCIRP) is one of the largest Open Access journal publishers. It is currently publishing more than 200 open access, online, peer-reviewed journals covering a wide range of academic disciplines. SCIRP serves the worldwide academic communities and contributes to the progress and application of science with its publication.

Other selected journals from SCIRP are listed as below. Submit your manuscript to us via either submit@scirp.org or Online Submission Portal.
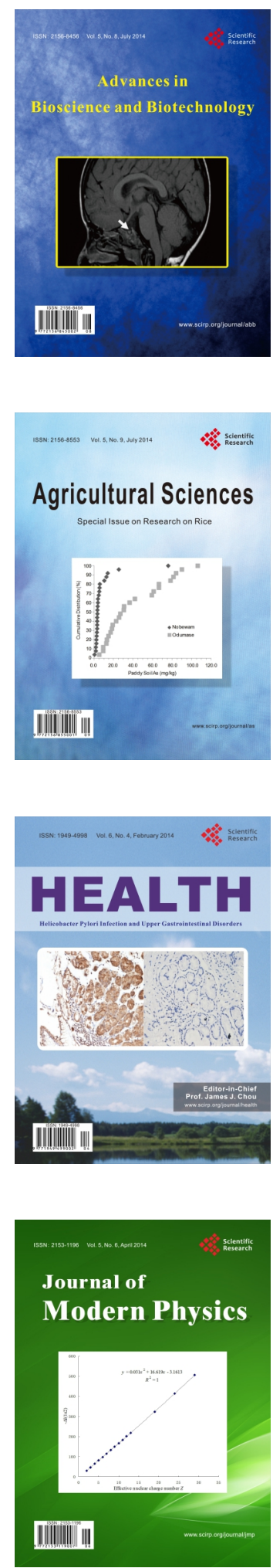
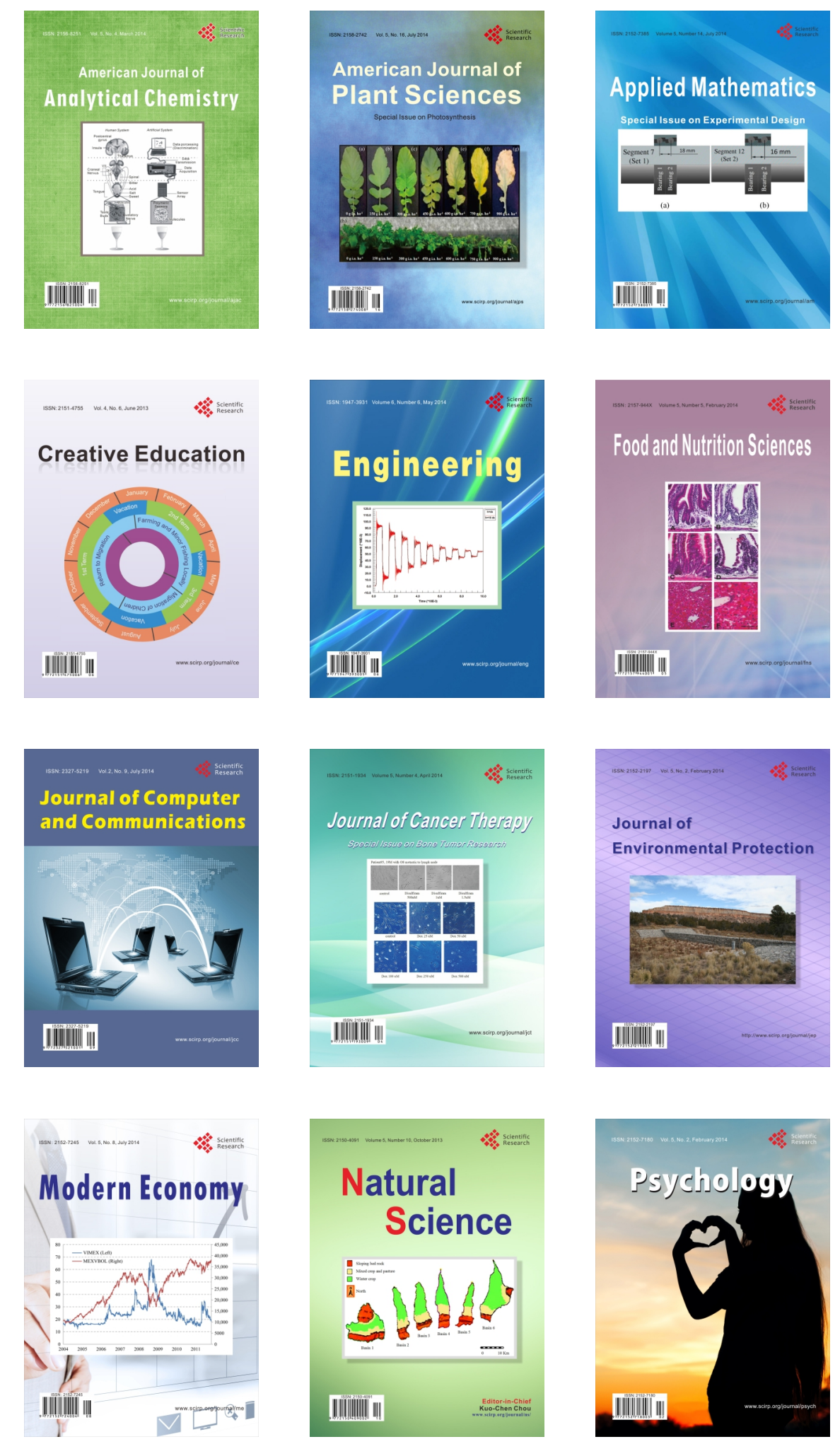